\title{
Rectal tonsil associated with Epstein-Barr virus
}

Reactive polypoid proliferation of lymphoid tissue has been described along the gastrointestinal tract [1]. Endoscopically, when a non-lymphomatous lymphoid reaction resembling tonsillar tissue is present in the rectum, the polyp is named as "rectal tonsil". Few cases have been reported in the literature $[1,2]$, and the etiology of this rare condition is unknown [3-5].

Here we describe the case of a 58-year-old man referred to our center with a 6month history of fresh bleeding from the rectum. A colonoscopy was performed and a delineated round, reddish, nodular aggregate measuring $4 \times 3 \times 3 \mathrm{~cm}$ was found ( $\mathbf{F i g . 1}$ ). A polypectomy was performed ( Fig. 2), and histological examination ( $\bullet$ Fig.3) revealed infiltration of mucosa, submucosa, and lamina propria of the colon by numerous lymphoid follicles. Immunohistochemical markers were positive for CD20+(B cells), and intraepithelial lymphocytes were positive for $\mathrm{CD} 3+$ (T cells). Epstein-Barr virus encoded RNA in situ hybridization was positive ( $\bullet$ Fig. 3f).

At 1- and 6-month follow-up, there was no recurrence of the lesion in the rectum. This case represents the first case of rectal tonsil associated with Epstein-Barr virus infection.

Endoscopy_UCTN_Code_CCL_1AD_2AZ

Competing interests: None

\section{P. Grube-Pagola' ${ }^{1}$, A. Canales-Kay², A. Meixueiro-Daza ${ }^{3}$, J. M. Remes- Troche $^{3}$}

${ }^{1}$ Laboratorio de Patología Digestiva, Veracruz, México

${ }^{2}$ Colorectal Surgery Private Practice, Veracruz, México

${ }^{3}$ Laboratorio de Fisiología Digestiva y Motilidad Gastrointestinal, Instituto de Investigaciones Médico-Biológicas, Universidad Veracruzana, Veracruz, México
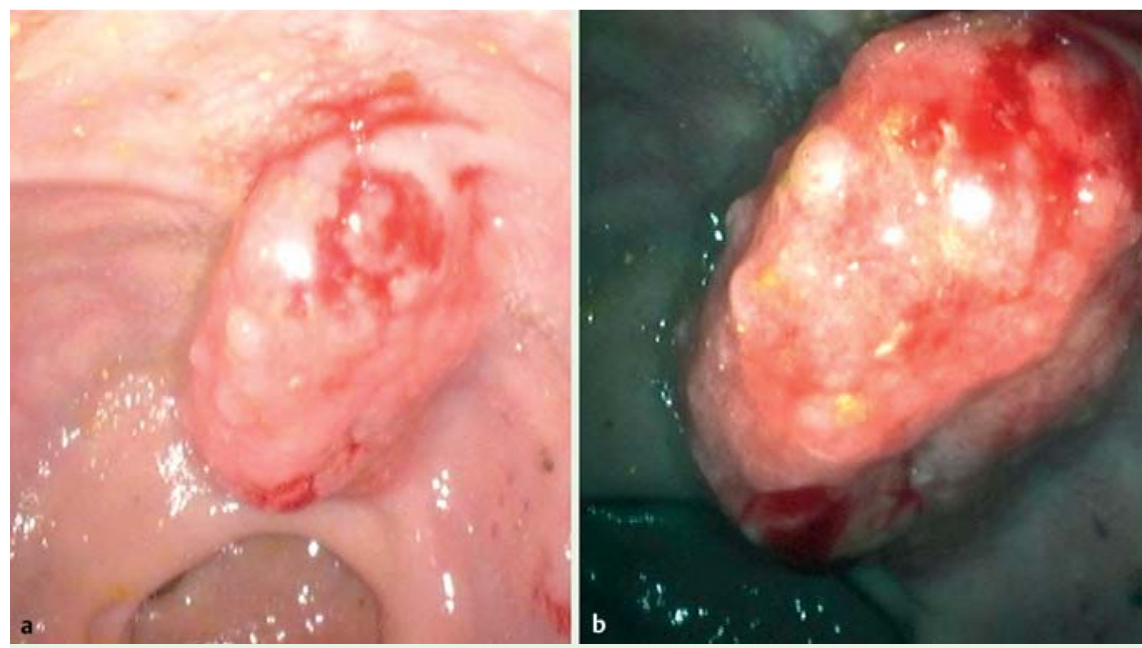

Fig. 1 a Colonoscopy revealed a well-delineated, round, reddish, nodular aggregate measuring $4 \times 3 \times 3 \mathrm{~cm}$, with follicles resembling the tonsils. b High definition colonoscopy using a digital filter (i-Scan 2, Pentax) emphasized the nodular component of the lesion.

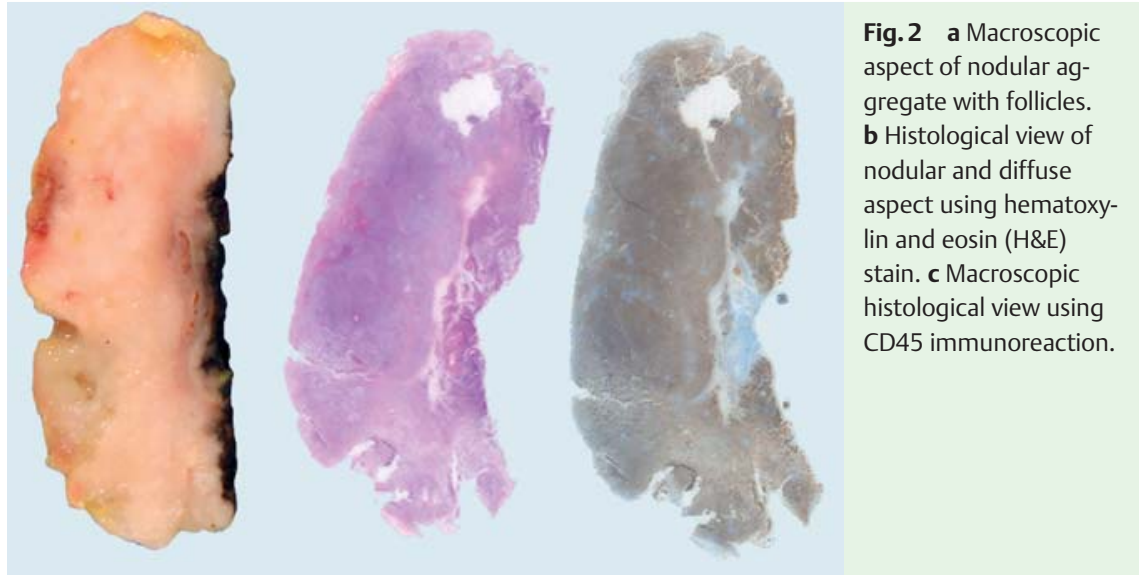

\section{References}

1 Farris $A B$, Lauwers GY, Ferry JA, Zukerberg $L R$. The rectal tonsil: a reactive lymphoid proliferation that may mimic lymphoma. Am J Surg Pathol 2008; 32: 1075-1079

2 O'Leary $A D$, Sweeney EC. Lymphoglandular complexes of the colon: structure and distribution. Histopathology 1986; 10: $267-$ 283

3 Lloyd J, Darzi A, Teare J, Goldin RD. A solitary benign lymphoid polyp of the rectum in a 51 year old woman. J Clin Pathol 1997; 50: 1034- 1035

4 Agaimy A, Mudter J, Märkl B, Chetty R. Cytomegalovirus infection presenting as isolated inflammatory polyps of the gastrointestinal tract. Pathology 2011; 43: 440-446

5 Cramer SF, Romansky S, Hulbert B et al. The rectal tonsil: a reaction to chlamydial infection? Am J Surg Pathol 2009; 33: 483-485

\section{Bibliography}

DOI http://dx.doi.org/

10.1055/s-0032-1310140

Endoscopy 2012; 44: E388-E389

(c) Georg Thieme Verlag KG

Stuttgart · New York

ISSN 0013-726X

\section{Corresponding author}

\section{J. M. Remes-Troche, MD}

Laboratorio de Fisiología Digestiva y Motilidad Gastrointestinal

Instituto de Investigaciones Médico-Biológicas Universidad Veracruzana

Veracruz

México

Fax: +52-229-2021231

jose.remes.troche@gmail.com

Fig. 3 see following page. 


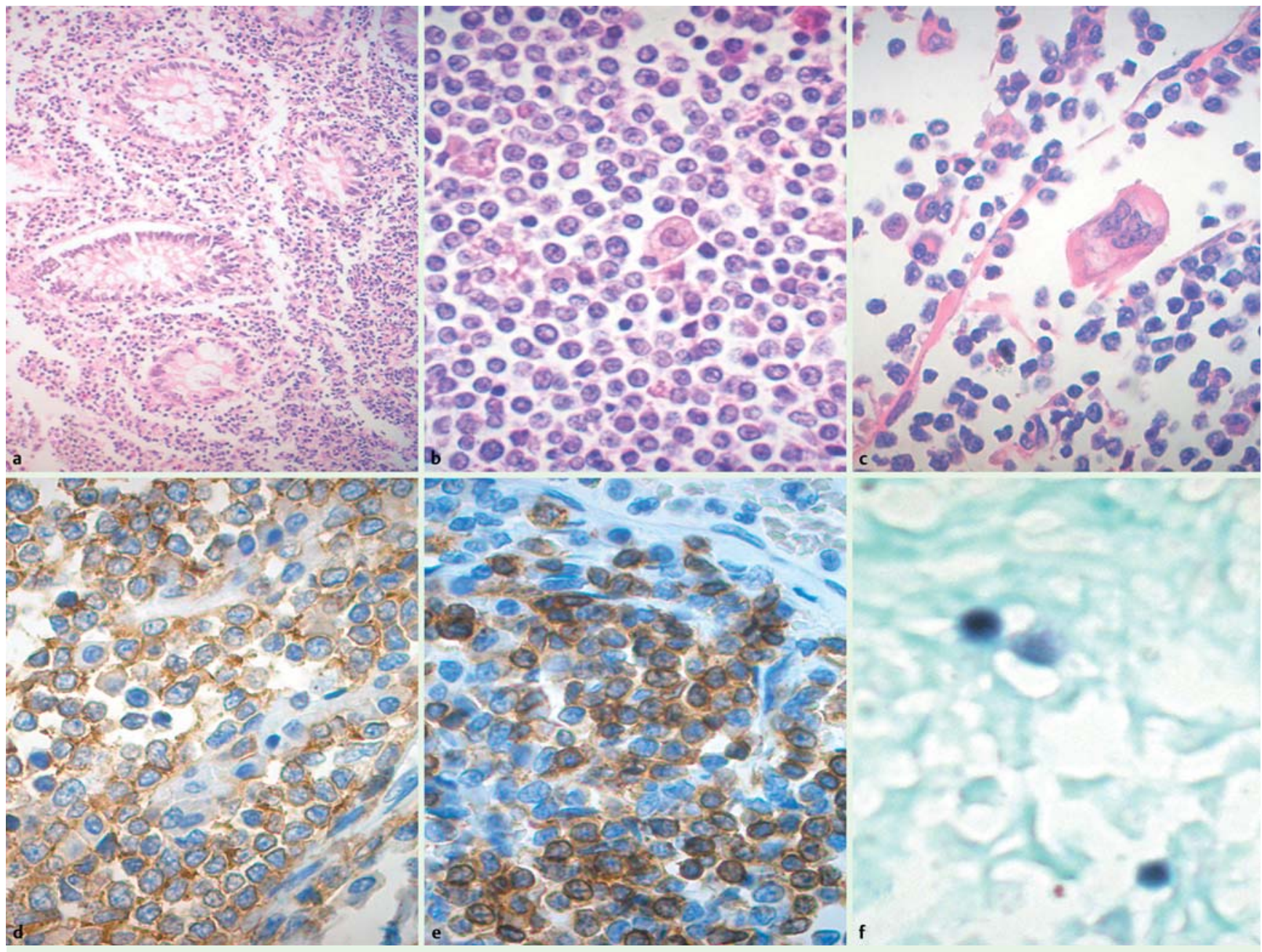

Fig. 3 a Residual colonic crypts; hematoxylin and eosin (H\&E) stain, $\times 200$. b Reactive lymphocytes and isolated immunoblasts (H\&E stain, $\times 800)$. c Binucleate reactive Reed-Sternberg-like cells (H\&E stain, $\times 800$ ). $\mathbf{d}$ Positive CD20 immunoreaction. e Positive CD3 immunoreaction. $\mathbf{f}$ Epstein-Barr virus-encoded RNA was positive (in situ hybridization for Epstein-Barr virus). 